\title{
THE LEND OF LIFESTYLE CHANGE AS A WAY TO ACHIEVE BETTER ECONOMIC \& MANAGEMENT SUCCESS
}

\author{
Marinel Cornelius Dinu ${ }^{332}$
}

https://doi.org/10.31410/itema.2018.969

\begin{abstract}
The development of society also requires special care for health. Health is a special human capital that benefits individuals and society. It is defined by the state of harmony established between the natural gifts received by people at birth and the choices set for a particular lifestyle throughout life.

The goal of this paper is to present several ways to balance the chosen lifestyle, to identify and eliminate the causes of the most common diseases and to show its influence on the entire societal development.

Research focuses on the role and effects of good changes in nutrition and behavior. When the right lifestyle is adopted, change is a gain (Reunen, 2015), with individual and social consequences. To put health problems into daily activities and habits involves identifying factors that directly affect people's lives and labor - such as shortcomings, dissatisfaction, or stress. In order to achieve better results, people use to adhere to different principles; however, they often receive opposite effects, which they know to read them correctly, their value and needs, and the real conditions of life (Pakholoc, 2013).

The objective of the paper is based on the challenges offered to all categories of people who decide to change their behavior and lifestyle by adopting alternatives to stress, sedentary and dysfunctional nutrition. Two hypotheses are considered (cognitive and emotional) to deepen the analysis between the desire to take a new initiative to get health and to develop new relationships between different actions such as the decision to change, the abandonment of wrong habits and the creation of a new mentality, for the individual and society benefit.
\end{abstract}

Keywords: life style, health, added value

\section{INTRODUCTION}

I $\mathrm{n}$ a society where are difficult situations (Viciu, 2012) in all fields of activity it is useful to identify best, measurable and successful best practices or activities to promote a healthy lifestyle (Robinson, 2014). It is intended to show how these practices are planned for people to be determined to adhere to the principles of an optimal lifestyle (Pakholoc, 2013).

Among individuals affected by stress (Cohen, 1983) and a sedentary lifestyle, rated "modern diseases", there are more and more those in the category of people who could manage a healthy lifestyle so that they are not affected by these "diseases" just outside the cities (Olshansky SJ, 2006). This is the challenge for young people and adults who want to adapt to sedentary work, as they attach to at least a few moments of physical activity (Groven, 2013) that positively influence the body and the mind.

The objective program is for better health through a balanced diet (Johansson, 1999), so that the diseases of the century do not affect the population. We know that balanced nutrition is not

\footnotetext{
${ }^{332}$ Bucharest University of Economic Studies, Ion Usurelu 16, M3, 39, Sect.5, Bucharest, Romania, 050234
} 
the best way to have optimal health. But diet can relieve disease symptoms, and a program to promote an ideal diet, as well as preventative medicine (UNIYAL, 2004), would support the move to a change in gaining health (Campbell, 2006). The benefits of balanced nutrition are noted in the central nervous system, inducing a sense of well-being. Dedicated time for scheduling activities to support a healthy diet such as practicing it induces this sense of relaxation. On the other hand, a sedentary life without a balanced diet is followed by a decrease in interest in change and in gaining health.

\section{CONTEXT}

The purpose of this paper is to suggest the option of change for gaining health through a changed lifestyle. Promoting a healthy diet also involves an assessment so that we should analyze the perspective of the purpose.

In the present study the paper proposes the following verification: there is a relationship between dedicating a time for lifestyle change and the perceived damage resulting from the omission of a healthy lifestyle.

Table 1: Health books and nutrition classes

\begin{tabular}{|c|c|c|}
\hline Read books of health & Buy health books & Take free nutrition classes \\
\hline $16 / 70$ & $31 / 70$ & $60 / 70$ \\
\hline $23 \%$ & $44 \%$ & $85,7 \%$ \\
\hline
\end{tabular}

Source: personal contribution

Figure 1: Health books and nutrition classes

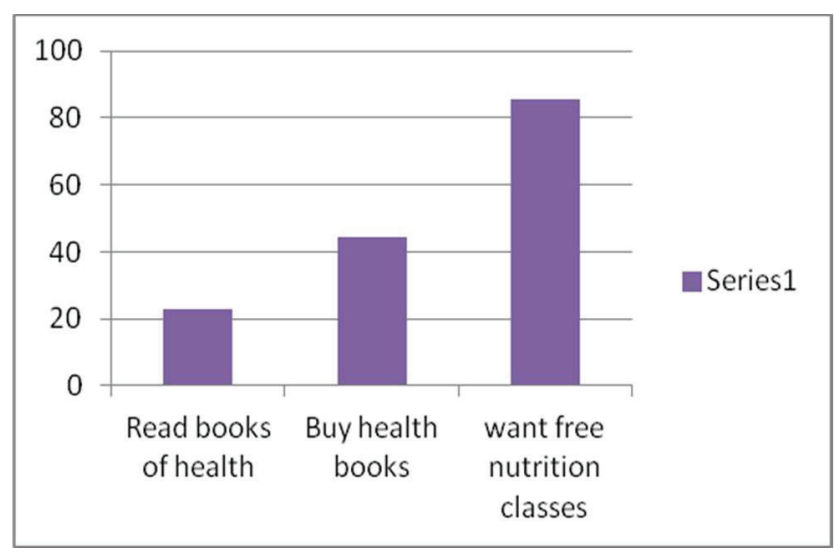

Source: personal contribution

Table 2: The levels of dangerous diseases

\begin{tabular}{|c|c|c|}
\hline Depression & Heart diseases & Diabetes \\
\hline $51 / 70$ & $65 / 70$ & $41 / 70$ \\
\hline $73 \%$ & $93 \%$ & $59 \%$ \\
\hline \multicolumn{3}{|c}{ Source: personal contribution }
\end{tabular}


Figure 2: The levels of dangerous diseases

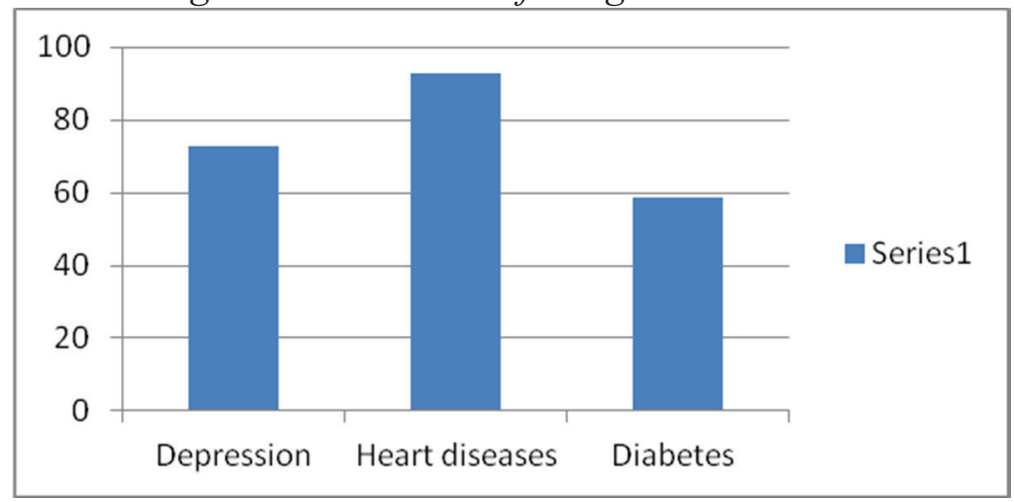

Source: personal contribution

It seems that the analysis results that the stress is on the second place among diseases subjects, which is a high-risk (73\%) compared to the level of heart disease (93\%).

Regarding the relationship between frequency of participation in physical activity and perceived stress levels, we found it below average among people.

It seems that those who devote time to exercise can be characterized as "active and healthier", is a "very good" physical condition.

This overview motivational indicates that persons, who devote time to get the change needed by food, realize the importance of healthy food in achieving a healthy lifestyle.

Table 3: Favorable contributions to diseases

\begin{tabular}{|c|c|c|}
\hline Smoke & Alcohol & Coffee \\
\hline $48 / 70$ & $53 / 70$ & $44 / 70$ \\
\hline $69 \%$ & $76 \%$ & $63 \%$ \\
\hline
\end{tabular}

Source: personal contribution

Table 3 shows that many people use alcohol (76\%) followed by smokers $(69 \%)$ and coffee drinkers $(63 \%)$, contributing favorably to the diseases listed above.

Figure 3: Favorable contributions to diseases

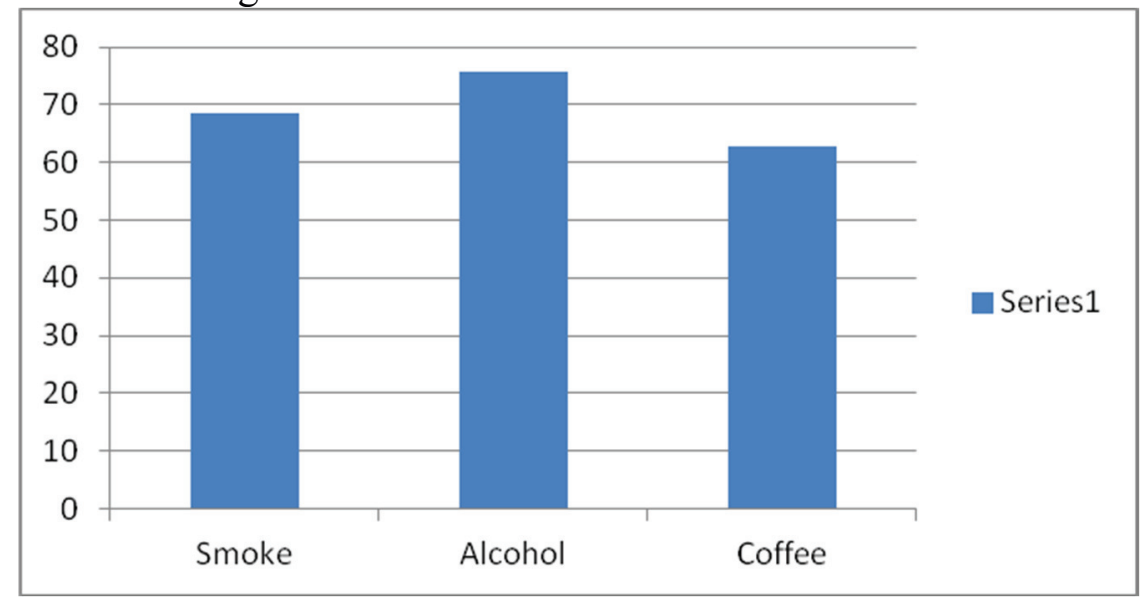

Source: personal contribution 


\section{CIRCUMSTANCES}

The new trend in health, adopted in large companies, supposes that in order to create a new style of approach, which includes the promotion of health in the products or services rendered an attraction to the investment. Companies tend to adopt the behavior of customer attractiveness through slogans that contain health analogies. Studies have shown that people have a defensive attitude towards moving to a healthy diet. However, young people and adults tend to have a balanced lifestyle. The key condition for increasing the success rate of a balanced lifestyle is good management of change. The term "change" is completely eliminated, the individual bears the universal footprint of an "ideal untouchable", regardless of the optimal results awaiting the completion or health that he will acquire. Without change management positions, every change of impact on society does not result. Failure to manage change will not result in the expansion of a healthy lifestyle. Such health campaigns would underline principles such as engagement and promulgation, which requires a radical shift in the organization and ways of gain tracking - in other words, the campaign aims to reorganize how it designs health gain through health programs from all points of view, sometimes involving profile readjustment.

To become a manager of change to gain program health, it's important to know how to manage change steps. Organizing tasks involves health gains and means to work in specific areas so that every step towards promoting a smart health program style becomes a step towards the skill of effective change perspective. As regards the setting of objectives, it is indicated that they are implemented in the long term and short-term identified tasks. Also, a periodical analysis of the achieved goals or of the progress made on various activities can become an indicator of performance to be taken into account.

In order to create a balance between personal life and collective life and to stay as efficient as possible for the time being, it is important when individual loading with some problems is delegated to other members of the team, others to be rejected from the beginning and for the average ones to identify technical solutions for faster resolutions (Reunen 2015).

Another way to succeed in fighting change is to prioritize, simplify or even eliminate some of the mechanisms of change. After some consideration, certain techniques of change must be removed from the strategy, and it is important to apply the mechanisms accepted in the process of change and the organization of more important mechanisms and techniques (Gulap, 2013). Rejecting additional strategies, even if they have a direct impact on the main activities that need to be done may most often be the correct approach, studies have shown that many techniques and strategies require efficiency deflation, the individual is forced to focus on different steps and procedures.

\section{CONCLUSIONS}

The conclusions that we have from the processing and interpreting data, validates our hypothetical research. Based on our data, we conclude that, for the proper health program of change and gain health, we should find a balance, and steps from strategies should be practiced daily little by little using practical solutions for combating unhealthy habits and sedentary lifestyle (Belanger, 1997).

To successfully accomplish the mission of becoming a moment of change, tasks can still be about starting from the overall image of the goals, then creating a small image in order to select one or two primary objectives per day. As regards the setting of objectives, it is indicated that 
they are implemented in the long term and short-term identified tasks. Also, a monthly analysis of the objectives achieved or of the progress made with regard to various changes may become an indicator of performance to be taken into account.

\section{REFERENCES}

[1] Cohen S. (1983) Positive Events and Social Supports as Buffers of Life Change Stress. Journal of Applied Social Psychology 13, 2: 99-125.

[2] Groven KS. (2013) Weight loss surgery as a tool for changing lifestyle? Med Health Care and Philos, Springer Science+Business Media Dordrecht 16: 699-708.

[3] Gulap M. (2013) Study on the Importance of Physical Education in Fighting Stress and a Sedentary Lifestyle, Elsevier Ltd.

[4] Johansson L. (1999) Healthy dietary habits in relation to social determinants and lifestyle factors. British Journal of Nutrition 81: 211-220.

[5] Olshansky SJ. (2006) A Potential Decline in Life Expectancy in the United States in the 21 st Century. The New England Journal of Medicine 352.

[6] Pakholok O. (2013) The Idea of Healthy Lifestyle and Its Transformation Into HealthOriented Lifestyle in Contemporary Society. Sage Open, Vol. 1(10), pp: 2.

[7] Reunen T. (2015) Human Factor in Time Management. Elsevier Ltd.

[8] Robinson N. (2014) Driving social impact with common global indicators for healthy lifestyle programs: Lessons learned. Food and Nutrition Bulletin 35: S 164.

[9] UNIYAL SK. (2004) Developmental Processes, Changing Lifestyle and Traditional Wisdom: Analyses from Western Himalaya. The Environmentalist 23: 307-312.

[10] Campbell , T Colin (2006) The China Study, Dallas: BenBella Books, Inc. 13.

[11] Viciu T-G; Vasile, Adrian; Costea, Carmen-Eugenia. (2012) A New Appraisal of the Relationship Between Economic Growth and the Economic Structure. Journal of Information Systems \& Operations Management 6. 